\title{
Corrigendum
}

\section{Increasing incidence of squamous cell carcinoma of the anus in Scotland, 1975-2002}

\section{DH Brewster and LA Bhatti}

British Journal of Cancer (2006) 95, 423. doi:I0.1038/sj.bjc.6603268 www.bjcancer.com

(c) 2006 Cancer Research UK

Correction to: British Journal of Cancer (2006) 95, 87-90. doi:10.1038/sj.bjc.6603175

Owing to an author error, the final paragraph within the results section of this paper quoted erroneous $P$-values. The final sentence of the Results section should read:
'Rates were somewhat higher in deprived areas, but this trend is only significant for females ( $P$-values for trend: 0.199 and 0.043 , for males and females, respectively).' 